Journal of Dairy Research

cambridge.org/dar

\section{Research Reflection}

Cite this article: Celi $\mathrm{P}$, Kindermann M, Tamassia LFM and Walker N (2020). Skeletal health, redox balance and gastrointestinal functionality in dairy cows: connecting bugs and bones. Journal of Dairy Research 87, 410-415. https://doi.org/10.1017/ S0022029920001090

Received: 15 May 2020

Revised: 5 October 2020

Accepted: 12 October 2020

First published online: 9 December 2020

\section{Keywords:}

Dairy cattle; gastrointestinal functionality; microbiome; redox balance; skeletal health

Author for correspondence:

Pietro Celi, Email: pietro.celi@dsm.com

(c) The Author(s), 2020. Published by Cambridge University Press on behalf of Hannah Dairy Research Foundation

\title{
Skeletal health, redox balance and gastrointestinal functionality in dairy cows: connecting bugs and bones
}

\section{Pietro Celi ${ }^{1,2}$, Maik Kindermann ${ }^{1}$, Luis F. M. Tamassia ${ }^{1}$ and Nicola Walker ${ }^{1}$}

${ }^{1}$ DSM Nutritional Products, Animal Nutrition and Health, Wurmisweg 576, Kaiseraugst, Switzerland and

${ }^{2}$ Melbourne School of Land and Environment, The University of Melbourne, Parkville, Vic. 3010, Australia

\begin{abstract}
This research reflection examines the physiological links between redox balance, skeletal health and gastrointestinal functionality in dairy cows. With the increase in demand of animal products caused by the growth in human population, the dairy industry needs to develop and implement innovative strategies which are profitable, sustainable and cow friendly. Redox balance, skeletal heath and gastrointestinal functionality are three key physiological systems that are often seen as independent entities. In this research reflection we intend to stress that the antioxidant system, bone health and the microbiome are intimately intertwined. Antioxidants are crucial for the maintenance of redox homeostasis and optimal immune function. Optimal gastrointestinal functionality is important to maintain animal performance, health and welfare. In particular, the intestinal microbiome is increasingly seen as a driver of health and disease. Vitamin D metabolism is pivotal not only for optimal skeletal health, but in light of all the extra-skeletal effect of vitamin $\mathrm{D}$, it is the foundation for optimal productive life. It makes sense to ask the question 'how are redox balance and the microbiome involved in the modulation of bone health and immune function?' In other words, are bugs and bones connected in dairy cows! The existing data available in the literature suggests that this might be the case. The characterization of the interactions between redox balance, skeletal health and the microbiome, will allow the development of a multisystem biological approach to refine nutritional interventions to improve dairy cattle health, welfare and productive longevity.
\end{abstract}

With the current forecast for the world's population to reach close to 11 billion by 2100 , it comes with no surprise that the demand for animal food products including dairy will increase. The implications for the dairy industry are numerous and far-reaching as it will have to develop and adopt strategies to increase productivity while maintaining cow health and welfare and safeguarding the environment. Notwithstanding the recent advances in dairy health and production, new developments in the dairy industry must encompass strategies that increase lifetime performance in order to meet the ever-growing demand for dairy products from the rapidly growing world population (McGrath et al., 2019). In the future, dairy farms will be bigger and highly modernized and for dairy farmers to feed the world's growing population within planetary boundaries, they will have to adopt technologies and husbandry practices that will provide improved cow lifetime performances, profitable dairy farms and sustainable agricultural practices (Britt et al., 2018).

Dairy cows of the future will be more robust with improved health and longevity, driven principally by improvements in genomic selection schemes. Welfare of dairy cattle will continue to receive increased attention, and dairy farm facilities will be modified to improve welfare of animals (Britt et al., 2018). Considering that nutritional interventions are arguably the easiest strategy that can be implemented at farm level (McGrath et al., 2019), the dairy industry has the responsibility to develop and implement alternative nutritional strategies which are good for its people (profitable), planet (sustainable) and for the cows (health and welfare). The maintenance of redox balance, skeletal heath and gastrointestinal functionality have been identified as key pillars around which veterinarians and nutritionist should develop interventions that would result in more resilient and healthy dairy cattle (Celi et al., 2017).

In this research reflection we intend to highlight the physiological links between the antioxidant system, vitamin D metabolism and the rumen microbiome. Antioxidants play a key role in the maintenance of redox homeostasis which is crucial for immune system, while bone metabolism and health are the foundation for optimal productive life. The role of the microbiome as driver of health and diseases has received significant attention by the scientific community, however there are very few studies investigating its role in the modulation of bone health and immune function. Our intent is to draw the reader's attention to the fact that biological systems, namely, redox balance, skeletal health and the microbiome, are connected. The characterization of the interactions between these systems will allow the development of 
targeted nutritional interventions that would enable the improvement of dairy cattle health, welfare and productive longevity.

\section{Redox balance}

When oxidant activity exceeds the neutralizing capacity of antioxidants it can result in oxidative stress which in ruminants has been associated with several diseases, including conditions that are relevant for animal production and welfare (Celi, 2011). An imbalance between pro-oxidants and antioxidants lead to oxidative stress, therefore the maintenance of redox balance is crucial for optimal ruminant health (Chauhan et al., 2014). The main pro-oxidants (reactive oxygen species, reactive nitrogen species) and antioxidants (endogenous and dietary) involved in the maintenance of redox balance in ruminants have been reviewed extensively (Miller et al., 1993; Lykkesfeldt and Svendsen, 2007; Celi, 2011; Chauhan et al., 2014; Sordillo and Mavangira, 2014).

Redox balance plays a key role in the modulation of metabolism, immunity, reproduction, health and welfare. In dairy cattle, redox balance can be disrupted at any time, however, the time around calving (transition period) and the first few weeks of life (neonatal period) are characterized by a higher risk of oxidative stress and incidence of diseases (Ranade et al., 2014; Abuelo et al., 2019). During these periods the requirement for nutrients and micronutrients, including antioxidants, is considerably increased (Pedernera et al., 2010), therefore, supplementing diets with micronutrients and antioxidants can prove to be useful in maintaining redox balance (Abuelo et al., 2015; Surai et al., 2019).

A relationship between dairy calf growth rates and antioxidant status has been reported (McGrath, 2016) and it has been proposed that dietary antioxidants can maintain redox balance in young ruminants, reducing the risk of disease and mortality while maintaining productive performance. In light of the observed accelerated growth of dairy calves and its association with increased lifetime productivity of dairy cows (Soberon and Van Amburgh, 2013), the use of dietary antioxidants seems to be a valid practical option to increase lifetime performances of dairy cattle (McGrath, 2016).

Redox balance is also implicated in the modulation of reproductive physiology in light of its involvement in the regulation of events such as oocyte maturation, steroidogenesis, regulation of follicular fluid environment, folliculogenesis, corpus luteal function, luteolysis and embryonic mortality (Talukder et al., 2017). The fact that antioxidant supplementation can improve reproductive outcomes in dairy cattle does not come as a surprise. While it is clear that maintaining redox balance in dairy cattle is crucial to maximize fertility (Talukder et al., 2017) and health (Abuelo et al., 2019), a better understanding of the factors involved in the control of redox balance will allow the verification of their success and effectiveness (Chauhan et al., 2016). More importantly, as antioxidants are routinely supplemented in dairy diets (Lean et al., 2013), the question is how much of which formulation(s) of antioxidants should be used to maintain redox balance. There is practical evidence in the literature suggesting that the supplementation of ruminant diets with supranutritional levels of antioxidants such as vitamin $\mathrm{E}$ and selenium can not only sustain redox balance but also maintain crucial physiological functions like thermoregulation, feed intake, respiratory physiology, rectal temperature, acid-base balance, inflammation and gastrointestinal functionality (Chauhan et al., 2014; Celi and Gabai, 2015).

\section{Skeletal health and redox balance}

Skeletal health is another of the many physiological function regulated by redox balance as suggested by epidemiological evidence linking dietary antioxidant intake and bone health (Rao and Rao, 2013). Redox balance seems to play a role in bone remodeling (Domazetovic et al., 2017). A disruption in redox balance results in decreased bone formation as the result of reduced differentiation and survival of osteoblasts, and activation of osteoclasts resulting in bone reabsorption (Rao and Rao, 2013). Moreover, antioxidant deficiency has been associated with reduction in bone formation ultimately resulting in osteoporosis (Domazetovic et al., 2017). Antioxidant enzymes such as glutathione peroxidase and catalase are considered markers of antioxidants defence mechanisms against bone resorption and osteoporosis (Rao and Rao, 2013). Recently, many dietary antioxidants have been reported to restore redox balance and skeletal health (Rao and Rao, 2013). For example, antioxidants such as vitamin $\mathrm{C}$ contribute to the maintenance of skeletal health by suppressing osteoclast activity and promoting osteoblast differentiation. Although vitamin $\mathrm{C}$ can be synthesized in tissues by ruminants, it is important to emphasize that vitamin $C$ is an important cofactor for collagen formation and synthesis of hydroxyproline and hydroxylysine, indicating that vitamin $C$ interacts with other nutritional factors such as vitamin E, vitamin D and calcium in the control of skeletal health (Sahni et al., 2015). Finally, dietary carotenoids have also been reported to play an important role for improving bone health (Sahni et al., 2015).

\section{Extraskeletal effects of vitamin D}

The mechanisms of disrupted skeletal health in dairy cows impairing their ability to maintain effective bone and mineral homeostasis have been recently reviewed (McGrath et al., 2015). The role of vitamin D and its metabolites in maintaining skeletal health and mineral homeostasis are very well established. However, the actions of vitamin D are not confined to the skeleton as vitamin D receptors (VDR) and vitamin D hydroxylases CYP24A1 and CYP27B1 are nearly ubiquitous, advocating for a variety of extraskeletal actions of the vitamin $\mathrm{D}$ endocrine system (Bikle, 2016; Bouillon et al., 2019). The potential for the bone to now be considered an endocrine organ firmly puts skeletal health of the modern day dairy cow at the forefront of science (McNeill and Anderson, 2012; Lean et al., 2014).

In both swine and poultry, the use of vitamin $\mathrm{D}_{3}$ and 25-OH-D 3 (25-hydroxycholecalciferol) has been shown to improve bone strength, calcification, immunity and muscle content, often resulting in less morbidity and mortality as well as greater productivity (Chou et al., 2009; Sugiyama et al., 2013). The next frontier of bone health research in dairy cows should be the characterization of the extraskeletal effects, such as the effects on metabolism, reproduction, muscle biology, immunity, and gastrointestinal functionality.

There is substantial evidence from published and new data that supports the hypothesis that in dairy cattle the skeleton has a pivotal role during the homeorhetic adaptation to lactation and that this relationship may be influenced by nutrition. Indeed, recent studies have demonstrated a link between $25-\mathrm{OH}-\mathrm{D}_{3}$ and energy metabolism in dairy cows (Lean et al., 2014; Rodney et al., 2018). In dairy cows, a dramatic increase in energy and nutrient requirements can be observed during the transition period, exposing them to negative energy and nutrient balance. The metabolic 
adaptations to negative energy balance require interactions of metabolic fuels and its failure may occur in various tissues resulting in several metabolic diseases (Drackley, 1999). Despite the transition period being the most studied period of the productive life of a dairy cow, the long-term physiological implications on responses like mammary gland function and fertility require a thorough assessment. Essential physiological function such as calcium homeostasis, lipid metabolism, insulin secretion, tissue sensitivity to insulin and the integration of these processes with other functions like redox balance are not fully elucidated yet. It has been observed that nutritional interventions administered before calving can increase milk yield, improve fertility and reduce the risk of metabolic diseases (Lean et al., 2014). It is also worth noting that correlations between energy and bone metabolism have been observed in dairy cows providing evidence to support a homeorhetic role for calcium metabolism in dairy cattle (Lean et al., 2014; Martinez et al., 2018b; Rodney et al., 2019). However, it is worth mentioning that vitamin $\mathrm{D}$ supplementation around the time of calving has not always succeeded in preventing hypocalcemia (Weiss et al., 2015). Considering the complex mechanisms involved in the control of calcium homeostasis in dairy cattle (DeGaris and Lean, 2008), further studies are required to evaluate the effectiveness of vitamin $\mathrm{D}$ supplementation to reduce hypocalcemia during early lactation. Although it has been reported that vitamin $\mathrm{D}$ has a high margin of safety when used at recommended levels (Celi et al., 2018), excessive intakes of vitamin $\mathrm{D}$ can result in intoxication in ruminants and future studies need to evaluate the safety of vitamin D supplementation for long periods of time.

Considering that VDRs are expressed in numerous tissues of the reproductive tract (Dokoh et al., 1983; Stumpf et al., 1987), reproductive physiology should also be considered in regard to skeletal health. It has been reported that vitamin $\mathrm{D}$ has a positive effect on reproductive physiology in cattle (Ward et al., 1971; Panda et al., 2001; Kemmis et al., 2006). Indeed, it has been observed that dairy cattle reproductive performance improved after vitamin D supplementation (Ward et al., 1971), and that calcitriol blood concentration is elevated during pregnancy (O'Brien et al., 2014). A recent study in transition dairy cows has reported that dietary $25-\mathrm{OH}-\mathrm{D}_{3}$ tended to improve pregnancy rate and reduced the days to pregnancy during the $305-\mathrm{d}$ lactation (Martinez et al., 2018a). The authors argue that metabolites of vitamin $\mathrm{D}$ such as $25-\mathrm{OH}-\mathrm{D}_{3}$ might have directly stimulated the VDRs in reproductive tissues (Lou et al., 2010), which might have resulted in positive effects on fertility. Another possibility is that the positive effect on reproductive function might have been indirect as cows fed $25-\mathrm{OH}-\mathrm{D}_{3}$ presented improved neutrophil function and reduced incidence of inflammatory diseases such as metritis, which are known to decrease fertility (Ribeiro et al., 2016). Therefore, the observed improved pregnancy rate might have been the consequence of the better health status induced by dietary 25-OH-D 3 (Martinez et al., 2018a).

Considering that VDR and 1- $\alpha$-hydroxylase are expressed in muscle fibers and myoblasts, it is not surprising that vitamin D plays a direct regulatory role in muscle physiology. Indeed, vitamin $\mathrm{D}$ is involved in the regulation of myogenesis, cell proliferation, differentiation, regulation of protein synthesis and mitochondrial metabolism (Montenegro et al., 2019). Lack of VDR disrupts muscle growth and development, as observed in VDR knockout mice which have smaller muscle fibers and aberrant myogenic regulatory factor expression (Dzik and Kaczor, 2019). Moreover, as the inflammatory processes reduce muscle protein accretion, decreasing the impact of the inflammatory response is a key strategy to sustain production performances. Considering that dairy beef cross cattle production is becoming a financially attractive opportunity for the dairy industry as it allows producers to produce calves that will yield better carcasses than purebred dairy breeds and thus attract higher prices, dietary supplementation of dairy cattle's diet with vitamin D, in light of its the well-known anti-inflammatory effects, represents a great opportunity for the dairy industry to increase profitability and sustainability. Indeed, dairy beef production generates around $33 \%$ of the greenhouse gases equivalents per unit weight of meat compared to traditional beef cattle production and thus $25-\mathrm{OH}-\mathrm{D}_{3}$ supplementation can increase meat yield and lower the carbon footprint of the dairy industry at the same time (Britt et al., 2018).

It is well known that both the innate and acquired immune responses are modulated by ligand dependent VDR functions. Indeed, VDR and vitamin D metabolic enzymes can be found in all cells of the innate and adaptive arms of the immune system (Bouillon et al., 2019). In cattle, calcitriol augments the production of nitric oxide and $\beta$-defensin antimicrobial peptides (Merriman et al., 2015), molecules that are toxic to bacteria, indicating a potential for targeted enhancement of defence against bacterial infections via the vitamin D pathway (Nelson et al., 2012). Macrophages are the main sources of the calcitriol that controls vitamin D-mediated immune responses. In bovine macrophages CYP27B1 is stimulated via toll-like receptor recognition of pathogen associated molecular patterns such as lipopolysaccharide, peptidoglycan, and mycobacterial lipopeptides. In macrophages, CYP27B1 facilitates the conversion of calcidiol to calcitriol, activating vitamin D-mediated immune responses (Nelson et al., 2010). Interestingly, CYP27B1 is expressed in the udder during mastitis in dairy cattle (Nelson et al., 2010). Although vitamin $\mathrm{D}$ treatments does not seem to prevent or cure mastitis, it reduced its negative impact on the cow (Lippolis et al., 2011). It has been reported that dietary $25-\mathrm{OH}-\mathrm{D}_{3}$ decreased the incidence of retained placenta and metritis and the percentage of cows with multiple diseases during the first $30 \mathrm{~d}$ in milk, which are likely related to the improved measures of immune function evaluated in neutrophils (Martinez et al., 2018a). While it is clear that vitamin D can modulate the immune system in dairy cattle, we still need clarity of understanding of the immunomodulatory effects of dietary $25-\mathrm{OH}-\mathrm{D}_{3}$ as this will allow the development of nutritional strategies to increase the resilience of dairy cattle to bacterial infection. These strategies have the potential to reduce the use of antibiotics in the dairy industry and thus might contribute to the decrease in antimicrobial resistance.

VDR and vitamin D metabolic enzymes have been localized in virtually all cells of both the innate and adaptive immune system. Moreover, there is now consensus that cells of the immune system produce $1,25(\mathrm{OH}) 2 \mathrm{D}_{3}$ locally and that expression of CYP27B1 in the immune system is regulated independently of that in the endocrine system that controls calcium homeostasis (Nelson et al., 2012). For example, there is evidence that in activated immune cells VDR controls several immune responses (Hewison, 2011). It has been observed that in cattle, 1,25(OH) $2 \mathrm{D}_{3}$ increases the production of antimicrobial peptides such as nitric oxide and $\beta$-defensin, (Nelson et al., 2012). Considering that vitamin $\mathrm{D}$ metabolism might be quite different in each system (skeletal, immune, digestive, etc.), it is reasonable to argue that the vitamin $\mathrm{D}$ requirements for each of these systems may 
also differ (Nelson et al., 2016). Nevertheless, the optimal 25(OH) $\mathrm{D}_{3}$ concentration for the dairy cattle immune system has not been established thus far. In vitro studies investigating the effect of different $25(\mathrm{OH}) \mathrm{D}_{3}$ concentrations on macrophage host defence responses suggest that $100 \mathrm{ng} / \mathrm{ml}$ should be an effective level (Nelson et al., 2010). However, despite the association between vitamin $\mathrm{D}$ deficiency and risk of respiratory infections, calves with a serum $25(\mathrm{OH}) \mathrm{D}_{3}$ concentration of about $175 \mathrm{ng} / \mathrm{ml}$ and experimentally challenged with respiratory syncytial virus (RSV), did not perform better than calves with serum $25(\mathrm{OH})$ $\mathrm{D}_{3}$ concentration of about $30 \mathrm{ng} / \mathrm{ml}$ in regard to severity the infection (Sacco et al., 2012). As reported above, however, there is evidence for dietary $25(\mathrm{OH}) \mathrm{D}_{3}$ to reduce the incidence of some peripartum diseases in dairy cattle (Martinez et al., 2018a); this apparent discrepancy needs to be addressed with further work investigating the relationship between serum $25(\mathrm{OH}) \mathrm{D}_{3}$ and infectious disease outcome in dairy cattle.

Vitamin D deficiency has been linked to disrupted gastrointestinal functionality (Christakos, 2012; De Santis et al., 2015), and although vitamin deficiencies do not seem to occur in modern dairy production systems, it should be noted that vitamin requirements of the modern dairy cow may be higher than those currently recommended by the NRC. The current understanding of gastrointestinal functionality encompasses not only the gastrointestinal (GI) microbiota including pathogens causing diseases, mortality and morbidity in dairy cattle, but also other key components such as diet, effective structure of the gastrointestinal barrier, host interaction with the GI microbiota, effective digestion and absorption of feed and effective maturation and development of innate and acquired immune functions (Celi et al., 2017). This novel definition of gut health focuses on the functionality of the whole GI system and on the complex interactions between all its components mentioned above. With this definition in mind, it is not surprising that skeletal health is also influenced by the GI microbiota and vice versa. Indeed, it has been reported that vitamin D influences the composition of the microbiota (Sun, 2018; Waterhouse et al., 2019), and that the gut microbiota regulates endocrine vitamin D metabolism (Bora et al., 2018). Vitamin $\mathrm{D}$ regulates the expression of tight junction proteins in the intestinal epithelial cells, thereby maintaining optimal intestinal barrier function (De Santis et al., 2015). In the intestinal mucosa, vitamin $\mathrm{D}$, together with vitamin $\mathrm{A}$, supports innate lymphoid cells that produce IL-22, suppressed IFN- $\gamma$ and IL-17 by T cells, and induces regulatory $\mathrm{T}$ cells (Cantorna et al., 2019). Vitamin $\mathrm{D}$ seems to shape the gut microbiota by modulating the intestinal epithelium and mucosal immune system and thus maintaining intestinal homeostasis (Cantorna et al., 2019). On the other end, the intestinal microbiota may regulate bone metabolism by influencing the relative activities of osteoclasts and osteoblasts through effects on the immune system and host metabolic pathways, as well as through the production of metabolites (Charles et al., 2015). It has been proposed that during eubiosis (balance between the gut microbiome and their host), there is a balance between the anti-osteoclastogenic and pro-osteoclastogenic pathways, however, during dysbiosis (disturbance in the balance between the gut microbiome and the host), the gut microbiome may promote osteoclast-mediated bone loss as a result of the increase in inflammatory cytokines which recruit more osteoclast precursors, promote osteoclast activity and reduce anti-osteoclast $\mathrm{T}$ cells (Charles et al., 2015). Several cytokines are involved in skeletal health and proinflammatory cytokines are believed to have osteoclastogenic effects (Jonsson et al., 2013). For example, tumor necrosis factor $\alpha$ (TNF- $\alpha$ ) and IL-1 have been shown to modulate the expression of receptor activator of nuclear factor $\kappa-\mathrm{B}$ (RANK), its ligand (RANKL), and osteoprotegerin (Jonsson et al., 2013). Osteoclastogenesis is the differentiation of osteoclast into multinucleated cells which leads to bone degradation and calcium mobilization. Osteoclastogenesis is initiated by the binding of RANKL to its receptor on osteoclasts. Osteoprotegerin on the other hand, inhibits osteoclastogenesis by acting as a decoy receptor for RANKL (Hatate et al., 2020). Changes in cytokine production in tissues and blood seems also to modulate calcium homeostasis during the parturient period, with potential implications for the incidence of peripartum hypocalcemia (Gray et al., 2007). While specific studies in this area are lacking in dairy cattle, the literature clearly highlights the biological links between redox balance, skeletal health and gastrointestinal functionality.

In conclusion, future dairy production and its sustainability depends on the development a larger understanding and practical application of concepts related to gastrointestinal functionality that imply complete holistic management of the production system. Nutritional strategies can reduce the incidence of health and welfare issues, but they need to be strategically integrated with management practices and breeding programs. The success of these strategies, however, is often hindered by the complexity of the interactions between cows and their environment. In dairy cattle, effective gastrointestinal functionality is vital in determining health, welfare and productive performance. Optimization of gastrointestinal functionality is crucial to increase nutrient digestibility and thus maximizing value from feed, to sustain host physiological functions such as innate and adaptive immunity and thus increasing resilience to environmental challenges, and finally, to maintain eubiotic conditions. The characterization of the interactions between the antioxidant system, vitamin D metabolism and the rumen microbiome will allow the development of strategic nutritional interventions aimed at improving skeletal health, redox balance and gastrointestinal functionality that would enable achieving optimal lifetime performance.

\section{References}

Abuelo A, Hernández J, Benedito JL and Castillo C (2015) The importance of the oxidative status of dairy cattle in the periparturient period: revisiting antioxidant supplementation. Journal of Animal Physiology and Animal Nutrition 99, 1003-1016.

Abuelo A, Hernández J, Benedito JL and Castillo C (2019) Redox biology in transition periods of dairy cattle: role in the health of periparturient and neonatal animals. Antioxidants 8, 20.

Bikle DD (2016) Extraskeletal actions of vitamin D. Annals of the New York Academy of Science 1376, 29-52.

Bora SA, Kennett MJ, Smith PB, Patterson AD and Cantorna MT (2018) The gut microbiota regulates endocrine vitamin $\mathrm{D}$ metabolism through fibroblast growth factor 23. Frontiers in Immunology 9, 408-408.

Bouillon R, Marcocci C, Carmeliet G, Bikle D, White JH, Dawson-Hughes B, Lips P, Munns CF, Lazaretti-Castro M, Giustina A and Bilezikian J (2019) Skeletal and extraskeletal actions of vitamin D: current evidence and outstanding questions. Endocrine Reviews 40, 1109-1151.

Britt JH, Cushman RA, Dechow CD, Dobson H, Humblot P, Hutjens MF, Jones GA, Ruegg PS, Sheldon IM and Stevenson JS (2018) Invited review: learning from the future - a vision for dairy farms and cows in 2067. Journal of Dairy Science 101, 3722-3741.

Cantorna MT, Snyder L and Arora J (2019) Vitamin A and vitamin D regulate the microbial complexity, barrier function, and the mucosal immune responses to ensure intestinal homeostasis. Critical Reviews in Biochemistry and Molecular Biology 54, 184-192. 
Celi P (2011) Oxidative stress in ruminants. In Mandelker L and Vajdovich P (eds), Studies on Veterinary Medicine. Oxidative Stress in Applied Basic Research and Clinical Practice, vol. 5. New York: Humana Press, pp. 191-231.

Celi P and Gabai G (2015) Oxidant/antioxidant balance in animal nutrition and health: the role of protein oxidation. Frontiers in Veterinary Science 2, 48 .

Celi P, Cowieson AJ, Fru-Nji F, Steinert RE, Kluenter AM and Verlhac V (2017) Gastrointestinal functionality in animal nutrition and health: new opportunities for sustainable animal production. Animal Feed Science and Technology 234, 88-100.

Celi P, Williams S, Engstrom M, McGrath J and La Marta J (2018) Safety evaluation of dietary levels of 25-hydroxyvitamin D3 in growing calves. Food and Chemical Toxicology 111, 641-649.

Charles JF, Ermann J and Aliprantis AO (2015) The intestinal microbiome and skeletal fitness: connecting bugs and bones. Clinical Immunology 159, 163-169.

Chauhan SS, Celi P, Leury BJ, Clarke IJ and Dunshea FR (2014) Dietary antioxidants at supranutritional doses improve oxidative status and reduce the negative effects of heat stress in sheep. Journal of Animal Science 92, 3364-3374.

Chauhan SS, Liu F, Leury BJ, Cottrell JJ, Celi P and Dunshea FR (2016) Functionality and genomics of selenium and vitamin E supplementation in ruminants. Animal Production Science 56, 1285-1298.

Chou SH, Chung TK and Yu B (2009) Effects of supplemental 25-hydroxycholecalciferol on growth performance, small intestinal morphology, and immune response of broiler chickens. Poultry Science 88, 23332341.

Christakos S (2012) Vitamin D deficiency: protective against enteric infection? American Journal of Physiology: Gastrointestinal and Liver Physiology 303, G1297-G1298.

DeGaris PJ and Lean IJ (2008) Milk fever in dairy cows: a review of pathophysiology and control principles. The Veterinary Journal 176, 58-69.

De Santis S, Cavalcanti E, Mastronardi M, Jirillo E and Chieppa M (2015) Nutritional keys for intestinal barrier modulation. Frontiers in Immunology 6, 612-612.

Dokoh S, Donaldson CA, Marion SL, Pike JW and Haussler MR (1983) The ovary: a target organ for 1,25-dihydroxyvitamin D3. Endocrinology 112, 200-206.

Domazetovic V, Marcucci G, Iantomasi T, Brandi ML and Vincenzini MT (2017) Oxidative stress in bone remodeling: role of antioxidants. Clinical Cases in Mineral and Bone Metabolism 14, 209-216.

Drackley JK (1999) Biology of dairy cows during the transition period: the final frontier. Journal of Dairy Science 82, 2259-2273.

Dzik KP and Kaczor JJ (2019) Mechanisms of vitamin D on skeletal muscle function: oxidative stress, energy metabolism and anabolic state. European Journal of Applied Physiology 119, 825-839.

Gray CP, St George TD and Jonsson NN (2007) Milk fever in dairy cattle: a novel hypothesis for an immune mediated aetiology. Cattle Practice 15, 277-282.

Hatate K, Kawashima C, Kayano M, Hanada M and Yamagishi N (2020) Blood markers of osteoclastic differentiation in periparturient dairy cows at different parities, with and without milk fever. Research in Veterinary Science 131, 301-305.

Hewison M (2011) Vitamin D and innate and adaptive immunity. In Gerald L (ed.), Vitamins \& Hormones, vol. 86, London, UK: Academic Press, pp. 23-62.

Jonsson NN, Fortes MRS, Piper EK, Vankan DM, de Cisneros JPJ and Wittek T (2013) Comparison of metabolic, hematological, and peripheral blood leukocyte cytokine profiles of dairy cows and heifers during the periparturient period. Journal of Dairy Science 96, 2283-2292.

Kemmis CM, Salvador SM, Smith KM and Welsh J (2006) Human mammary epithelial cells express CYP27B1 and are growth inhibited by 25Hydroxyvitamin D-3, the major circulating form of vitamin D-3. Journal of Nutrition 136, 887-892.

Lean IJ, VanSaun R and DeGaris PJ (2013) Mineral and antioxidant management of transition dairy cows. Veterinary Clinics of North America: Food Animal Practice 29, 367-386.

Lean IJ, DeGaris PJ, Celi P, McNeill DM, Rodney RM and Fraser DR (2014) Influencing the future: interactions of skeleton, energy, protein and calcium during late gestation and early lactation. Animal Production Science 54, 1177-1189.

Lippolis JD, Reinhardt TA, Sacco RA, Nonnecke BJ and Nelson CD (2011) Treatment of an intramammary bacterial infection with 25-hydroxyvitamin D(3). PLoS ONE 6, e25479.

Lou YR, Molnár F, Peräkylä M, Qiao S, Kalueff AV, St-Arnaud R, Carlberg C and Tuohimaa $\mathbf{P}$ (2010) 25-Hydroxyvitamin $\mathrm{D}(3)$ is an agonistic vitamin $\mathrm{D}$ receptor ligand. The Journal of Steroid Biochemistry and Molecular Biology 118, 162-70.

Lykkesfeldt J and Svendsen O (2007) Oxidants and antioxidants in disease: oxidative stress in farm animals. The Veterinary Journal 173, 502-511.

Martinez N, Rodney RM, Block E, Hernandez LL, Nelson CD, Lean IJ and Santos JEP (2018a) Effects of prepartum dietary cation-anion difference and source of vitamin D in dairy cows: health and reproductive responses. Journal of Dairy Science 101, 2563-2578.

Martinez N, Rodney RM, Block E, Hernandez LL, Nelson CD, Lean IJ and Santos JEP (2018b) Effects of prepartum dietary cation-anion difference and source of vitamin D in dairy cows: lactation performance and energy metabolism. Journal of Dairy Science 101, 2544-2562.

McGrath JJ (2016) Accelerated pre-weaning growth rates in dairy calves: do antioxidants have a place? Animal Production Science 56, 1275-1284.

McGrath JJ, Savage DB and Godwin IR (2015) The role and potential advantages of vitamin D metabolites in maintaining calcium status in highproducing dairy herds. Animal Production Science 55, 1081-1089.

McGrath J, Duval SM, Tamassia LFM, Kindermann M, Stemmler RT, de Gouvea VN, Acedo TS, Immig I, Williams SN and Celi P (2019) Nutritional strategies in ruminants: a lifetime approach. Research in Veterinary Science 116, 28-39.

McNeill D and Anderson S (2012) Year Bone as an endocrine organ and the mineral nutrition of the dairy cow. Proceedings of the International Conference on Livestock Production and Veterinary Technology, pp. 220225 .

Merriman KE, Kweh MF, Powell JL, Lippolis JD and Nelson CD (2015) Multiple beta-defensin genes are upregulated by the vitamin D pathway in cattle. Journal of Steroid Biochemistry and Molecular Biology 154, 120-129.

Miller JK, Brzezinska-Slebodzinska E and Madsen FC (1993) Oxidative stress, antioxidants, and animal function. Journal of Dairy Science 76, 2812-2823.

Montenegro KR, Cruzat V, Carlessi R and Newsholme P (2019) Mechanisms of vitamin D action in skeletal muscle. Nutrition Research Reviews 32, 1-13.

Nelson CD, Reinhardt TA, Thacker TC, Beitz DC and Lippolis JD (2010) Modulation of the bovine innate immune response by production of 1alpha,25-dihydroxyvitamin $\mathrm{D}(3)$ in bovine monocytes. Journal of Dairy Science 93, 1041-1049.

Nelson CD, Reinhardt TA, Lippolis JD, Sacco RE and Nonnecke BJ (2012) Vitamin D signaling in the bovine immune system: a model for understanding human vitamin D requirements. Nutrients 4, 181-196.

Nelson CD, Lippolis JD, Reinhardt TA, Sacco RE, Powell JL, Drewnoski ME, O'Neil M, Beitz DC and Weiss WP (2016) Vitamin D status of dairy cattle: outcomes of current practices in the dairy industry. Journal of Dairy Science 99, 10150-10160.

O'Brien KO, Li S, Cao C, Kent T, Young BV, Queenan RA, Pressman EK and Cooper EM (2014) Placental CYP27B1 and CYP24A1 expression in human placental tissue and their association with maternal and neonatal calcitropic hormones. Journal of Clinical Endocrinology and Metabolism 99, 1348-1356.

Panda DK, Miao D, Tremblay ML, Sirois J, Farookhi R, Hendy GN and Goltzman D (2001) Targeted ablation of the 25-hydroxyvitamin D 1alpha-hydroxylase enzyme: evidence for skeletal, reproductive, and immune dysfunction. Proc Natl Acad Sci USA 98, 7498-7503.

Pedernera M, Celi P, García SC, Salvin HE, Barchia I and Fulkerson WJ (2010) Effect of diet, energy balance and milk production on oxidative stress in early-lactating dairy cows grazing pasture. The Veterinary Journal $\mathbf{1 8 6}$ 352-357.

Ranade R, Talukder S, Muscatello G and Celi P (2014) Assessment of oxidative stress biomarkers in exhaled breath condensate and blood of dairy heifer calves from birth to weaning. The Veterinary Journal 202, 583-587. 
Rao LG and Rao AV (2013) Oxidative stress and antioxidants in the risk of osteoporosis - role of the antioxidants lycopene and polyphenols. In Flores MV (ed.), Topics in Osteoporosis, Croatia, pp. 117-161.

Ribeiro ES, Gomes G, Greco LF, Cerri RLA, Vieira-Neto A, Monteiro PLJ Jr, Lima FS, Bisinotto RS, Thatcher WW and Santos JEP (2016) Carryover effect of postpartum inflammatory diseases on developmental biology and fertility in lactating dairy cows. Journal of Dairy Science 99, 2201-2220.

Rodney RM, Martinez NP, Celi P, Block E, Thomson PC, Wijffels G, Fraser DR, Santos JEP and Lean IJ (2018) Associations between bone and energy metabolism in cows fed diets differing in level of dietary cation-anion difference and supplemented with cholecalciferol or calcidiol. Journal of Dairy Science 101, 6581-6601.

Rodney RM, Celi P, McGrath JJ, Golder HM, Anderson ST, McNeill DM, Fraser DR and Lean IJ (2019) Metabolic and production responses to calcidiol treatment in mid-lactation dairy cows. Animal Production Science 59, 449-460.

Sacco RE, Nonnecke BJ, Palmer MV, Waters WR, Lippolis JD and Reinhardt TA (2012) Differential expression of cytokines in response to respiratory syncytial virus infection of calves with high or low circulating 25-hydroxyvitamin D3. PLoS ONE 7, e33074-e33074.

Sahni S, Mangano KM, McLean RR, Hannan MT and Kiel DP (2015) Dietary approaches for bone health: lessons from the Framingham osteoporosis study. Current Osteoporosis Reports 13, 245-255.

Soberon F and Van Amburgh ME (2013) Lactation biology symposium: the effect of nutrient intake from milk or milk replacer of preweaned dairy calves on lactation milk yield as adults: a meta-analysis of current data. Journal of Animal Science 91, 706-712.
Sordillo LM and Mavangira V (2014) The nexus between nutrient metabolism, oxidative stress and inflammation in transition cows. Animal Production Science 54, 1204-1214.

Stumpf WE, Sar M and O'Brien LP (1987) Vitamin D sites of action in the pituitary studied by combined autoradiography-immunohistochemistry. Histochemistry 88, 11-16.

Sugiyama T, Kusuhara S, Chung TK, Yonekura H, Azem E and Hayakawa T (2013) Effects of 25-hydroxy-cholecalciferol on the development of osteochondrosis in swine. Animal Science Journal 84, 341-349.

Sun J (2018) Dietary vitamin D, vitamin D receptor, and microbiome. Current Opinion in Clinical Nutrition and Metabolism Care 21, 471-474.

Surai PF, Kochish II, Fisinin VI and Juniper DT (2019) Revisiting oxidative stress and the use of organic selenium in dairy cow nutrition. Animals 9, 462.

Talukder S, Kerrisk KL, Gabai G and Celi P (2017) Role of oxidantantioxidant balance in reproduction of domestic animals. Animal Production Science 57, 1588-1597.

Ward G, Marion GB, Campbell CW and Dunham JR (1971) Influences of calcium intake and vitamin $\mathrm{D}$ supplementation on reproductive performance of dairy cows. Journal of Dairy Science 54, 204-206.

Waterhouse M, Hope B, Krause L, Morrison M, Protani MM, Zakrzewski $\mathbf{M}$ and Neale RE (2019) Vitamin D and the gut microbiome: a systematic review of in vivo studies. European Journal of Nutrition 58, 2895-2910.

Weiss WP, Azem E, Steinberg W and Reinhardt TA (2015) Effect of feeding 25-hydroxyvitamin D3 with a negative cation-anion difference diet on calcium and vitamin D status of periparturient cows and their calves. Journal of Dairy Science 98, 5588-5600. 